\title{
STUDI PREDIKSI PENGGUNAAN ENERGI LISTRIK DI DESA SANGLEPONGAN KABUPATEN ENREKANG DENGAN MENGGUNAKAN METODE MOVING AVERAGE (MA)
}

\author{
Asdaqul Khair ${ }^{1}$, Hilda Ashari ${ }^{2}$, Sanatang ${ }^{3}$ \\ ${ }^{1}$ Pendidikan Teknik Elektro, Universitas Negeri Makassar \\ asdaqulkhair@gmail.com \\ ${ }^{2}$ Pendidikan Teknik Elektro, Universitas Negeri Makassar \\ hildaashari@unm.ac.id \\ ${ }^{3}$ Pendidikan Teknik Informatika dan Komputer, Universitas Negeri Makassar \\ sanatang.unm@gmail.com
}

\begin{abstract}
ABSTRAK
Penelitian ini adalah penelitian deskriptif yang bertujuan untuk mengetahui jumlah kebutuhan energi listrik di Desa Sanglepongan Kabupaten Enrekang pada tahun 2021 dengan metode moving average (MA). Objek penelitian pada penelitian ini adalah jumlah kebutuhan energi listrik di Desa Sanglepongan sedangkan subjek penelitian pada penelitian ini adalah data historis penggunaan energi listrik di Desa Sanglepongan. Teknik pengumpulan data yang digunakan adalah teknik observasi dan dokumentasi. Teknik analisis data yang digunakan adalah teknik analisis statistik deskriptif. Berdasarkan hasil penelitian diperoleh bahwa metode moving average (MA) baik digunakan untuk memprediksi dengan |MAPE| (mean absolute percentage error) sebesar 10\%, kemudian prediksi jumlah kebutuhan energi listrik di Desa Sanglepongan pada tahun 2021 adalah sebesar $107.656 \mathrm{~W}$ atau naik sebesar 4,13\% dari tahun 2019 dan $0.37 \%$ dari tahun 2020.
\end{abstract}

Kata Kunci: Prediksi, Energi Listrik, Moving Average (MA)

\section{STUDY OF ELECTRICITY USE PREDICTION IN SANGLEPONGAN VILLAGE, ENREKANG REGENCY USING THE MOVING AVERAGE (MA) METHOD}

\begin{abstract}
This study is a descriptive study that aims to determine the amount of electrical energy demand in Sanglepongan Village, Enrekang Regency in 2021 using the moving average (MA) method. The object of research in this study is the amount of electrical energy demand in Sanglepongan Village, while the research subject in this study is historical data on the use of electrical energy in Sanglepongan Village. Data collection techniques used are observation and documentation techniques. The data analysis technique used is descriptive statistical analysis technique. Based on the research results, it is found that the moving average (MA) method is good for predicting with $|M A P E|$ (mean absolute percentage error) of $10 \%$, then the prediction of the amount of electrical energy demand in Sanglepongan Village in 2021 is $107,656 \mathrm{~W}$ or an increase of $4.13 \%$ from 2019 and $0.37 \%$ from 2020.
\end{abstract}

Keyword: Prediction, Electrical Energy, Moving Average (MA) 


\section{PENDAHULUAN}

Energi listrik merupakan salah satu hal yang sangat penting dalam kehidupan manusia. Energi listrik sangat dibutuhkan dalam beberapa sektor, yaitu sektor rumah tangga, industri, bisnis, dan umum. Energi listrik menjadi kebutuhan pokok di zaman modern ini karena hampir semua aktivitas manusia akan berhubungan dengan energi listrik. PT. PLN (Perusahaan Listrik Negara) merupakan perusahaan penyedia tenaga listrik yang dibentuk oleh pemerintah dan diberi hak serta tanggung jawab untuk mengelola dan mendistribusikan tenaga listrik melalui suatu kuasa usaha karena energi listrik merupakan salah satu hal yang sangat penting dalam kehidupan manusia.

Di negara berkembang seperti Indonesia, aktivitas yang membutuhkan konsumsi energi listrik dari waktu ke waktu terus mengalami peningkatan. Peningkatan kebutuhan energi listrik tersebut mengharuskan pihak penyedia energi listrik dalam hal ini PT. PLN dapat menyalurkan kebutuhan listrik konsumen agar kebutuhan energi listrik tetap terpenuhi. [1] dijelaskan bahwa konsumen adalah setiap orang atau badan yang membeli tenaga listrik dari pemegang izin usaha penyedia tenaga listrik, dan pada ayat 6 dijelaskan bahwa usaha penjualan tenaga listrik adalah kegiatan usaha listrik kepada konsumen. Berdasarkan peraturan pemerintah tersebut, hubungan antara konsumen dengan pihak penyedia tenaga listrik sangatlah penting. PT PLN selaku lembaga penyedia dan penyalur utama listrik ke masyarakat secara tidak langsung menjadi tulang punggung kesejahteraan hidup dan kemajuan perekonomian Indonesia.

Desa Sanglepongan merupakan salah satu desa di kawasan Kecamatan Curio Kabupaten Enrekang,Sulawesi Selatan. Desa Ini mengalami pertumbuhan penduduk dalam kurun waktu 3 tahun terakhir 1.482 jiwa menjadi 1.545 jiwa per tahun 2020, kenaikannya sebesar 4,25\% dalam 3 tahun terakhir Adapun kenaikan jumlah konsumen listrik PLN dalam kurun waktu 3 tahun terakhir adalah dari 184 konsumen menjadi 191 konsumen kenaikannya sebesar 3,8\% dalam 3 tahun terakhir, konsumen tersebut terbagi menjadi 2 sektor yaitu sektor rumah tangga dan sektor umum seperti rumah ibadah, sekolah, fasilitas kesehatan dan kantor pemerintaahan [2]. Peningkatan jumlah konsumen listrik PLN di Desa Sanglepongan tidak lepas dari laju pertumbuhan penduduk dan juga laju pembangunan dan pengembangan infrastruktur desa. Selama kurun waktu 5 tahun terakhir pembangunan dan pengembangan insfrastruktur di Desa Sanglepongan cukup signifikan, di antaranya: pembangunan gedung sekolah bertingkat, pembangunan mesjid berlantai dua, pembangunan jalan tani, pembangunan saluran irigasi pertanian, pemasangan lampu jalan pembangunan dan pengembangan fasilitas kesehatan dan olahraga. Pertumbuhan jumlah penduduk dan peningkatan laju pembangunan dan pengembangan infrastruktur desa akan sejalan dengan meningkatnya kebutuhan energi listrik [3], penggunaan tenaga listrik diprekirakan akan selalu meningkat setiap tahunnya. Hal ini dikarenakan oleh semakin berkembangnnya kebutuhan masyarakat yang harus dipenuhi. Banyak faktor yang berpengaruh terhadap tingkat kebutuhan energi listrik, seperti : faktor ekonomi, kependudukan, kewilayaan dan faktor lainnya. Permintaan kebutuhan listrik tersebut harus diikuti dengan penyediaan tenaga listrik oleh pihak penyedia tenaga listrik, dalam hal ini adalah PT. PLN cabang Kabupaten Enrekang, agar energi listrik tetap tersedia sehingga mampu memenuhi kebutuhan konsumen akan energi listrik.

PT PLN dalam upaya menjaga ketersediaan energi listrik tersebut harus mempunyai perencanaan dan pengembangan kebijakan yang baik dalam menjamin ketersediaan energi listrik. Salah satu upaya dalam mewujudkan perencanaan dan pengembangan kebijakan energi listrik di masa depan adalah dengan melakukan prediksi (forecasting) jumlah kebutuhan energi listrik jangka menengah, dalam hal ini memprediksi kebutuhan energi listrik 12 bulan yang akan datang (1 tahun yang akan datang). Prediksi (forecasting) adalah suatu proses memperkirakan secara sistematis tentang sesuatu yang paling mungkin terjadi di masa depan berdasarkan informasi masa lalu dan sekarang yang dimiliki, agar kesalahannya (selisi antara sesuatu yang terjadi dengan hasil perkiraan) dapat diperkecil. Prediksi tidak harus memberikan jawaban secara pasti kejadian yang akan terjadi, melainkan berusaha untuk mencari jawaban sedekat mungkin yang akan terjadi [3]. [4] membagi jangka waktu prediksi menjadi tiga kategori yaitu : (1) Prediksi jangka pendek yaitu prediksi untuk jangka waktu kurang dari 3 bulan. (2) Prediksi jangka menengah yaitu prediksi untuk jangka waktu 3 bulan sampai 3 tahun. (3) Prediksi jangka panjang yaitu prediksi untuk jangka waktu lebih dari 3 tahun.

Ada banyak metode yang digunakan untuk memprediksi jumlah kebutuhan energi listrik salah satu metode yang bisa digunakan adalah metode moving average (MA) (metode rata-rata bergerak). Metode moving average digunakan untuk meratakan deret berkala suatu data yang bergelombang. Dasar yang dipakai untuk menghitung rata-rata bergerak, dilakukan dengan mencari nilai rata-rata dari 
beberapa tahun secara berturut-turut, sehingga diperoleh nilai rata-rata bergerak secara teratur atas dasar jumlah tahun tertentu. Metode moving average (MA) dapat digunakan untuk memprediksi kebutuhan energi listrik jangka pendek, jangka menengah maupun jangka panjang.

\section{METODE PENELITIAN}

\section{A. Jenis Penelitian}

Jenis penelitian yang digunakan pada penelitian ini adalah penelitian kuantitatif deskriptif. Penelitian kuantitatif deskriptif adalah suatu proses menemukan pengetahuan yang menggunakan data berupa angka sebagai alat menganalisis keterangan mengenai apa yang ingin diketahui. Penelitian ini menggunakan data historis penggunaan energi listrik di Desa sanglepongan tahun 2019 dan 2020 untuk melakukan prediksi penggunaan energi listrik di Desa Sanglepongan Tahun 2021 dengan menggunakan metode moving average (MA).

\section{B. Waktu dan Lokasi Penelitian}

Penelitian akan dilaksanakan di Desa Sanglepongan dan kantor PT. PLN ULP Lakawan Kabupaten Enrekang. Penelitian dilakukan dari tanggal 15 Desember 2020 sampai 17 Februari 2021.

\section{Desain Penelitian}

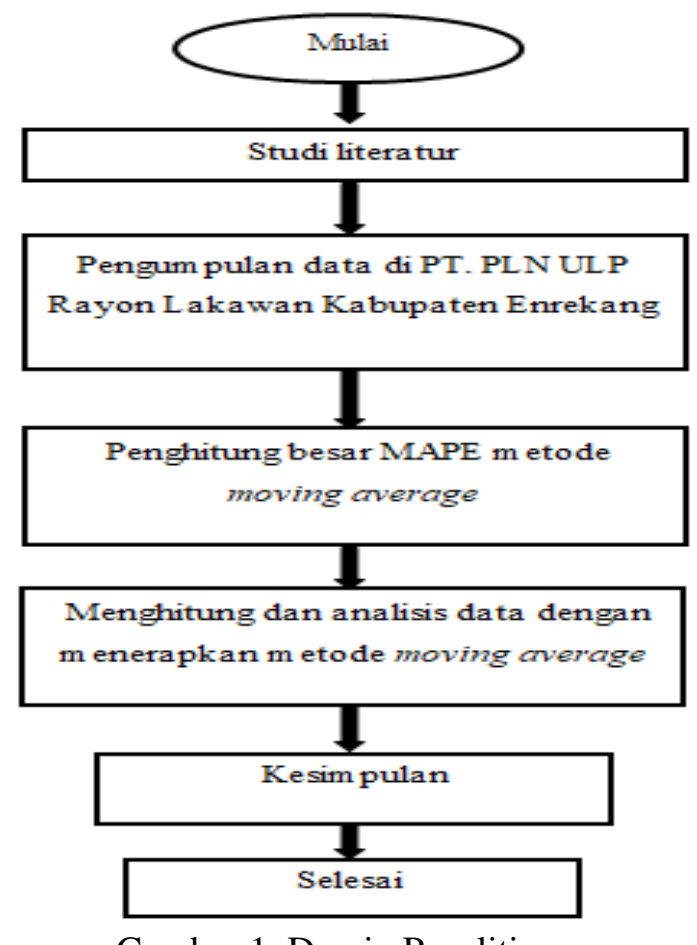

Gambar 1. Desain Penelitian

\section{HASIL DAN PEMBAHASAN}

\section{A. HASIL PENELITIAN}

1. Hasil Observasi Penggunaan Energi Listrik dan Jumlah Pelanggan

Berdasarkan hasil observasi, berikut ini adalah deskripsi hasil observasi tentang data historis penggunaan energi listrik di Desa Sanglepongan Kecamatan Curio Kabupaten Enrekang yang dilakukan di PT PLN ULP Lakawan Kabupaten Enrekang :

TABEL 1. HASIL OBSERVASI PENGGUNAAN ENERGI LISTRIK DI DESA SANGLEPONGAN, ENREKANG

\begin{tabular}{|c|c|c|c|c|}
\hline \multirow{2}{*}{ No } & \multirow{2}{*}{$\begin{array}{l}\text { Jenis Dokumen } \\
\text { yang dibutuhkan }\end{array}$} & \multicolumn{2}{|c|}{$\begin{array}{c}\text { Ketersediaan } \\
\text { data }\end{array}$} & \multirow{2}{*}{ Keterangan } \\
\hline & & Ada & $\begin{array}{c}\text { Tidak } \\
\text { ada }\end{array}$ & \\
\hline 1 & $\begin{array}{l}\text { Jumlah } \\
\text { penggunaan energi } \\
\text { listrik di Desa } \\
\text { Sanglepongan } \\
\text { Kecamatan Curio } \\
\text { Kabupaten } \\
\text { Enrekang }\end{array}$ & $\sqrt{ }$ & & $\begin{array}{l}2 \text { tahun } \\
\text { terakhir }\end{array}$ \\
\hline 2 & $\begin{array}{l}\text { Jumlah pelanggan } \\
\text { listrik di Desa } \\
\text { Sanglepongan } \\
\text { Kecamatan Curio } \\
\text { Kabupaten } \\
\text { Enrekang }\end{array}$ & $\sqrt{ }$ & & $\begin{array}{l}2 \text { tahun } \\
\text { terakhir }\end{array}$ \\
\hline
\end{tabular}

Berdasarkan Tabel 1 dapat dilihat bahwa hasil observasi tentang penggunaan energi listrik di Desa Sanglepongan Kecamatan Curio Kabupaten Enrekang sangat membantu dalam melakukan perhitungan prediksi (forecasting) dalam penelitian ini.

2. Penggunaan Energi Listrik dan Jumlah Pelanggan

Bedasarkan Tabel 2 menunjukkan bahwa jumlah penggunaan energi listrik di Desa Sanglepongan mengalami fluktuasi atau naik turun setiap bulannya. Tabel 2, menunjukkan bahwa jumlah penggunaan energi listrik di Desa Sanglepongan mengalami fluktuasi kenaikan dan penurunan penggunaan energi listrik perbulannya. Tabel 2 menunjukkan pada tahun 2019 mengalami fluktuasi kenaikan penggunaan energi listrik sebanyak 6 kali yaitu pada bulan Februari, April, Juni, Juli, September, dan November. Tabel 2 menunjukkan bahwa pada tahun 2019 mengalami fluktuasi penurunan penggunaan energi listrik sebanyak 5 kali yaitu pada bulan Maret, Mei, Agustus, Oktober dan Desember. Tabel 2 menunjukkan persentase jumlah rata-rata kenaikan penggunaan energi listrik perbulan yaitu sebesar 6,16 $\%$ dan persentase rata-rata penurunan penggunaan energi listrik perbulannya yaitu sebesar 7,51\% 
TABEL 2. JUMLAH PENGGUNAAN ENERGI LISTRIK \& PELANGGAN LISTRIK DI DESA SANGLEPONGAN KECAMATAN CURIO KABUPATEN ENREKANG TAHUN 2019

\begin{tabular}{|c|c|c|c|c|}
\hline Tahmm & Bulan & $\begin{array}{c}\text { Jumlah } \\
\text { penggunaan } \\
\text { energi } \\
\text { listrik (W) }\end{array}$ & $\begin{array}{l}\text { Kenaikan } \\
\text { penggunaan energi } \\
\text { listrik dari bulan } \\
\text { sebelumnya (\%) }\end{array}$ & $\begin{array}{l}\text { Penurunan } \\
\text { penggunaan } \\
\text { energi listrik } \\
\text { dari bulan } \\
\text { sebelumnnya. } \\
(\%)\end{array}$ \\
\hline \multirow{12}{*}{2019} & Januari & 8.296 & - & - \\
\hline & Februari & 8.565 & 3,24 & - \\
\hline & Maret & 7.771 & - & 9,27 \\
\hline & April & 8.690 & 11,83 & - \\
\hline & Mei & 8.473 & - & 2,50 \\
\hline & Juni & 9.365 & 10,53 & - \\
\hline & Juli & 9.527 & 1,73 & - \\
\hline & Agustus & 8.594 & - & 9,79 \\
\hline & September & 9.142 & 6,38 & - \\
\hline & Oktober & 8.309 & - & 9,11 \\
\hline & November & 8.578 & 3,24 & - \\
\hline & Desember & 7.987 & - & 6,89 \\
\hline \multicolumn{2}{|c|}{ Jumlah } & 103.297 & 36,94 & 37,56 \\
\hline \multicolumn{2}{|c|}{ Rata-ratakenaikan } & - & 6,16 & - \\
\hline \multicolumn{2}{|c|}{ Rata-rata penumunan } & - & - & 7,51 \\
\hline
\end{tabular}

TABEL 3. JUMLAH PENGGUNAAN ENERGI LISTRIK \& JUMLAH PELANGGAN LISTRIK DI DESA SANGLEPONGAN KECAMATAN CURIO KABUPATEN ENREKANG TAHUN 2020

\begin{tabular}{ccccc}
\hline Tahun & Bulan & $\begin{array}{c}\text { Jumlah } \\
\text { penggunaan } \\
\text { energi } \\
\text { listrik (W) }\end{array}$ & $\begin{array}{c}\text { Kenaikan } \\
\text { penggunaan } \\
\text { energi listrik } \\
\text { dari bulan } \\
\text { sebelumnya (\%) }\end{array}$ & $\begin{array}{c}\text { Penurunan } \\
\text { penggunaan } \\
\text { energi listrik dari } \\
\text { bulan sebelumaxa } \\
(\%)\end{array}$ \\
\hline Januari & 8.619 & 7,91 & - \\
& Februari & 8.720 & 1,17 & - \\
& Maret & 8.158 & - & 6,44 \\
& April & 8.337 & 2,19 & - \\
2020 & Mei & 9.369 & 12,38 & - \\
& Juni & 10.230 & 9,19 & - \\
& Juli & 9.373 & - & 8,38 \\
& Agustus & 8.727 & - & 6,89 \\
& September & 9.410 & 7,83 & - \\
Oktober & 8.713 & - & 7,41 \\
November & 8.883 & 1,95 & - \\
Desember & 8.723 & - & 1,8 \\
\hline Jumlah & 107.262 & 42,62 & - \\
Rata-rata kenaikan & - & 6,09 & 6,18 \\
Rata-rata penurunan & - & - &
\end{tabular}

Tabel 3 menunjukkan pada tahun 2020 mengalami fluktuasi kenaikan penggunaan energi listrik sebanyak 7 kali yaitu pada bulan Januari, Februari, April, Mei, Juni, Juli, September, dan November. Tabel 3 menunjukkan pada tahun 2020 mengalami fluktuasi penurunan penggunaan energi listrik sebanyak 5 kali yaitu pada bulan Maret, Juli, Agustus, Oktober, dan Desember. Tabel 3 menunjukkan persentase jumlah rata-rata kenaikan penggunaan energi listrik perbulannya di desa Sanglepongan yaitu sebesar 6,09\%, dan persentase jumlah penurunan rata-rata penggunaan energi listrik di Desa Sanglepongan perbulannya yaitu sebesar $6,18 \%$.
Berdasarkan karakteristik tersebut penggunaan energi listrik di Desa Sanglepongan pada tahun 2019 dan 2020 dapat digunakan sebagai acuan untuk melakukan prediksi (forecasting) pada tahun yang akan datang. Murahartawaty mengungkapkan bahwa prediksi kuantitatif hanya dapat digunakan apabila: adanya informasi tentang keadaan lain, informasi tersebut dapat dituliskan dalam bentuk data, dapat diasumsikan bahwa pola yang lalu akan berkelanjutan pada masa yang akan datang. Berdasarkan pernyataan tersebut maka penggunaan energi listrik di Desa Sanglepongan pada tahun 2019 dan 2020, dapat digunakan untuk melakukan prediksi penggunaan energi listrik di tahun 2021 , karena pola datanya atau karakteristiknya yang hampir sama dan diprediksikan pola data itu akan berulang di tahun berikutnya.

\section{B. PEMBAHASAN}

1. Pengujian Metode Moving Average (MA) Untuk Prediksi (Forecasting) Pada Periode Bulan Juli Desember 2020

Metode yang digunakan untuk menghitung kesalahan prediksi dari hasil prediksi untuk periode bulan Juli-Desember 2020 adalah persamaan AE (average error), dan MAPE (mean absolute percentage error), hasil perhitungannya sebagai berikut:

TABEL 4. PREDIKSI PENGGUNAAN ENERGI LISTRIK MENGGUNAKAN METODE MOVING AVERAGE (MA)

\begin{tabular}{llcccc}
\hline No & Bulan & $\begin{array}{c}\text { Data } \\
\text { aktual } \\
\mathrm{x}_{\mathrm{i}}(\mathrm{W})\end{array}$ & $\begin{array}{c}\text { Hasil } \\
\text { Prediksi } \\
\mathrm{F}_{\mathrm{i}}(\mathrm{W})\end{array}$ & $\begin{array}{c}\text { Selisih } \\
\text { hasil } \\
\text { Prediksi } \\
\mathrm{e}_{\mathrm{i}}(\mathrm{W})\end{array}$ & $\begin{array}{c}\text { Selisih } \\
\text { Absolut Hasil } \\
\text { Prediksi }\left|\mathrm{x}_{\mathrm{i}}\right| \\
(\mathrm{W})\end{array}$ \\
\hline 1 & Juli & 9.373 & 8.905 & 468 & 468 \\
2 & Agustus & 8.727 & 9.031 & -303 & 303 \\
3 & September & 9.410 & 9.032 & 378 & 378 \\
4 & Oktober & 8.713 & 9.281 & -528 & 528 \\
5 & November & 8.883 & 9.303 & -420 & 420 \\
6 & Desember & 8.723 & 9.222 & -499 & 499 \\
\hline Jumlah & 53.829 & 54.774 & -904 & 2.596 \\
\hline
\end{tabular}
$\mathrm{AE}=\frac{\sum \mathrm{e}_{\mathrm{i}}}{\mathrm{n}}=-150|\mathrm{AE}|=150$

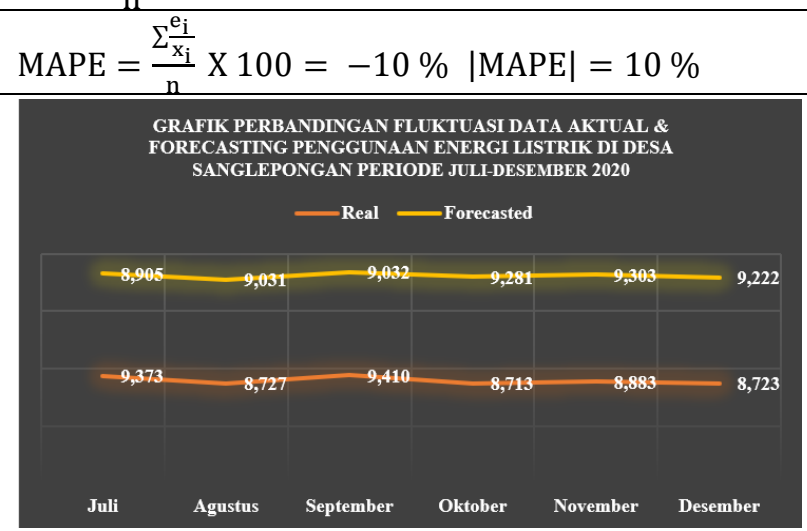

Gambar 2. Grafik Perbandingan Fluktuasi Data Aktual \& Data Hasil Forecasting Penggunaan Energi Listrik 
Berdasarkan hasil penelitian yang diperoleh pada Tabel 4, tingkat MAPE (Mean Absolute Percentage Error) metode moving average untuk memprediksi jumlah penggunaan energi listrik di Desa Sanglepongan Kabupaten Enrekang pada periode bulan Juli-Desember 2021 sebesar 10\%. Persentase sebesar $10 \%$ menunjukkan bahwa metode moving average baik digunakan untuk memprediksi jumlah kebutuhan energi listrik di Desa Sanglepongan Pada Tahun 2021, hal ini sejalan dengan teori Reghina (2020), yaitu metode prediksi dengan MAPE sebesar $10 \%$ baik digunakan untuk memprediksi (forecasting).

2. Prediksi (forecasting) Menggunakan Metode Moving Average (MA) Untuk Periode Bulan Januari - Desember 2021

TABEL 5. HASIL PERHITUNGAN PREDIKSI (FORECASTING) PENGGUNAAN ENERGI LISTRIK DI DESA SANGLEPONGAN PADA TAHUN 2021

\begin{tabular}{|c|c|c|c|c|}
\hline Tahun & Bulan & $\begin{array}{l}\text { Jumlah } \\
\text { penggunaan } \\
\text { energi listrik } \\
\text { (W) }\end{array}$ & $\begin{array}{c}\text { Kenaikan } \\
\text { penggunaan } \\
\text { energi listrik } \\
\text { dari bulan } \\
\text { sebelumnya } \\
(\%) \\
\end{array}$ & $\begin{array}{c}\text { Penurunan } \\
\text { penggunaan } \\
\text { energi listrik } \\
\text { dari bulan } \\
\text { sebelumnya } \\
(\%) \\
\end{array}$ \\
\hline \multirow{12}{*}{2021} & Januari & 9.151 & $6,17 \%$ & - \\
\hline & Februari & 8.997 & $3,18 \%$ & - \\
\hline & Maret & 8.943 & $9,62 \%$ & - \\
\hline & April & 8.974 & $7,64 \%$ & - \\
\hline & Mei & 8.912 & - & $4,88 \%$ \\
\hline & Juni & 8.94 & - & $12,61 \%$ \\
\hline & Juli & 8.949 & - & $4,52 \%$ \\
\hline & Agustus & 8.981 & $2,91 \%$ & - \\
\hline & $\begin{array}{l}\text { Septemb } \\
\text { er }\end{array}$ & 8.957 & - & $4,81 \%$ \\
\hline & Oktober & 8.951 & $2,73 \%$ & - \\
\hline & $\begin{array}{l}\text { Novemb } \\
\text { er }\end{array}$ & 8.952 & $0,78 \%$ & - \\
\hline & $\begin{array}{l}\text { Desemb } \\
\text { er }\end{array}$ & 8.949 & $2,59 \%$ & - \\
\hline \multicolumn{2}{|l|}{ Jumlah } & 107.656 & $35,62 \%$ & $26,83 \%$ \\
\hline \multicolumn{2}{|c|}{$\begin{array}{l}\text { Rata-Rata } \\
\text { Kenaikan }\end{array}$} & - & $4,45 \%$ & - \\
\hline \multicolumn{2}{|c|}{$\begin{array}{l}\text { Rata-Rata } \\
\text { Penurunan }\end{array}$} & - & - & $6,71 \%$ \\
\hline
\end{tabular}

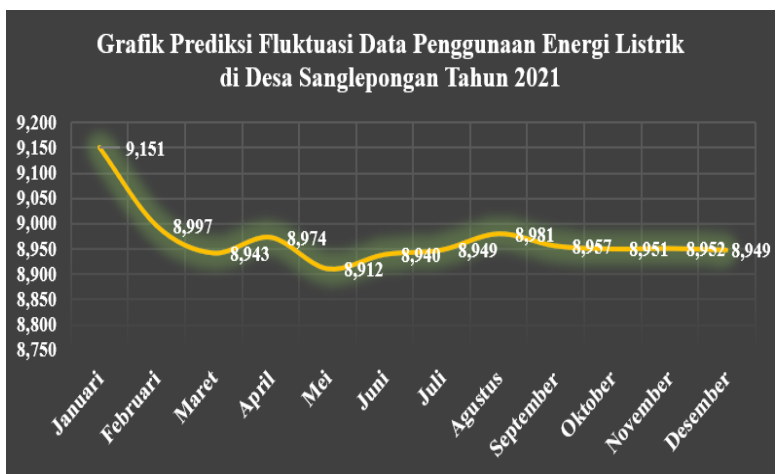

Gambar 3. Grafik Prediksi Fluktuasi Penggunaan Energi Listrik di Desa Sanglepongan Tahun 2021

Berdasarkan Tabel 5 hasil penelitian menunjukkan bahwa prediksi jumlah kebutuhan energi listrik di Desa Sanglepongan Tahun 2021 sebesar $107.656 \mathrm{~W}$, dari hasil prediksi tersebut menunjukkan bahwa pada bulan-bulan tertentu mengalami fluktuasi atau penurunan dan peningkatan jumlah kebutuhan energi pada setiap bulan yang berbeda. Hal ini sejalan dengan teori yang dikemukan oleh [5] bahwa kebutuhan konsumen bersamaan waktu mengakibatkan terjadinya puncak dan lembah pada saat konsumen tidak menggunakan peralatan listrik.

TABEL 6. HASIL PERHITUNGAN SELISIH DATA AKTUAL $2019 \& 2020$ DENGAN DATA HASIL PREDIKSI

(FORECASTING) PENGGUNAAN ENERGI LISTRIK DI DESA SANGLEPONGAN PADA TAHUN 2021

\begin{tabular}{|c|c|c|c|c|c|c|}
\hline $\begin{array}{l}\mathrm{N} \\
\mathrm{o}\end{array}$ & Bulan & $\begin{array}{l}\text { Data } \\
\text { aktual } \\
\text { tahun } \\
2019 \\
x_{2019} \\
(\mathrm{~W})\end{array}$ & $\begin{array}{c}\text { Data } \\
\text { aktual } \\
\text { tahun } \\
2020 \\
x_{2010} \\
\text { (W) }\end{array}$ & $\begin{array}{c}\text { Data } \\
\text { hasil } \\
\text { prediksi } \\
\text { tahun } \\
2021 \\
F_{2021} \\
(\mathrm{~W}) \\
\end{array}$ & $\begin{array}{c}\text { Selisih } \\
\text { data } \\
2019- \\
2021 \\
e_{2019-2021} \\
\text { (W) }\end{array}$ & $\begin{array}{c}\text { Selisih data } \\
2020-2021 \\
e_{2019-2021}(\mathrm{~W} \\
)\end{array}$ \\
\hline 1 & Januari & 8.296 & 8.619 & 9.149 & 855 & 532 \\
\hline 2 & Februari & 8.565 & 8.720 & 8.996 & 432 & 277 \\
\hline 3 & Maret & 7.771 & 8.158 & 8.943 & 1.172 & 785 \\
\hline 4 & April & 8.690 & 8.337 & 8.973 & 284 & 637 \\
\hline 5 & Mei & 8.473 & 9.369 & 8.911 & 439 & -457 \\
\hline 6 & Juni & 9.365 & 10.230 & 8.939 & -425 & -1.290 \\
\hline 7 & Juli & 9.527 & 9.373 & 8.947 & -578 & -424 \\
\hline 8 & Agustus & 8.594 & 8.727 & 8.978 & 387 & 254 \\
\hline 9 & $\begin{array}{l}\text { Septembe } \\
\mathrm{r}\end{array}$ & 9.142 & 9.410 & 8.955 & -185 & -453 \\
\hline 10 & Oktober & 8.309 & 8.713 & 8.949 & 642 & 238 \\
\hline 11 & $\begin{array}{l}\text { Novembe } \\
\mathrm{r}\end{array}$ & 8.578 & 8.883 & 8.950 & 374 & 69 \\
\hline 12 & Desember & 7.987 & 8.723 & 8.940 & 962 & 226 \\
\hline \multicolumn{2}{|r|}{ Jumlah } & $\begin{array}{c}103.29 \\
7 \\
\end{array}$ & $\begin{array}{c}107.26 \\
2 \\
\end{array}$ & $\begin{array}{c}107.65 \\
6 \\
\end{array}$ & & \\
\hline \multicolumn{7}{|c|}{ Persentase Kenaikan 2019-2020 = 3,84\% } \\
\hline \multicolumn{7}{|c|}{ Persentase Kenaikan 2019-2021 = 4,22\% } \\
\hline Per & ntase Kenaik & 2020-20 & $=0,37 \%$ & & & \\
\hline
\end{tabular}

Berdasarkan Tabel 6 diperoleh hasil bahwa, jumlah penggunaan energi listrik di Desa Sanglepongan terus mengalami peningkatan. Hasil penelitan tersebut sejalan dengan teori yang dikemukakan [3], yang mengatakan bahwa penggunaan tenaga listrik diprekirakan akan selalu meningkat setiap tahunnya. Hal ini dikarenakan semakin berkembangnnya kebutuhan masyarakat yang harus dipenuhi.

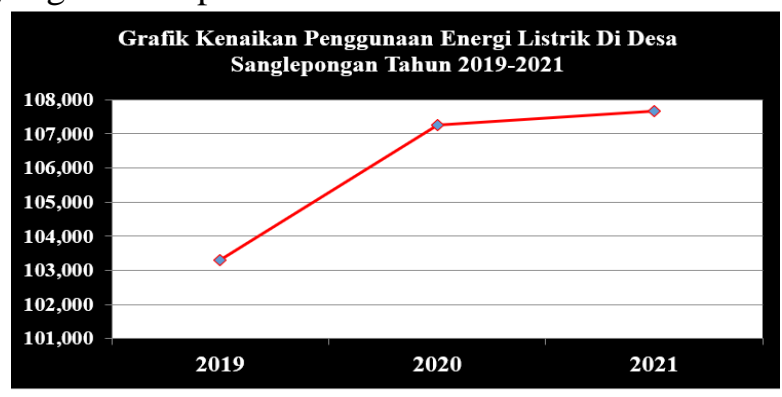

Gambar 4. Kenaikan Penggunaan Energi Listrik 


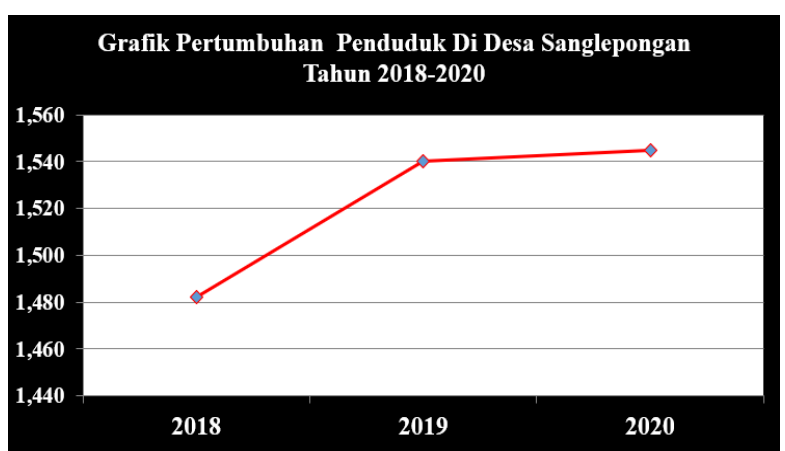

Gambar 5. Grafik Pertumbuhan Penduduk Di

Desa Sanglepongan Tahun 2018-2020

Berdasarkan Gambar 4 dan Gambar 5, hasil penelitian menunjukkan bahwa kenaikan kebutuhan listrik di Desa Sanglepongan dalam 3 tahun terakhir berbanding lurus dengan pertumbuhan penduduk. Artinya semakin naik pertumbuhan penduduk, maka kebutuhan akan energi listrik juga meningkat.

\section{SIMPULAN}

Penelitian ini bertujuan untuk mengetahui bertujuan untuk mengetahui prediksi jumlah kebutuhan energi listrik di Desa Sanglepongan Kecamatan Curio Kabupaten Enrekang pada tahun 2021 dengan menggunakan metode moving average (MA). Berdasarkan data hasil penelitian diperoleh kesimpulan sebagai berikut :

1. Jumlah kebutuhan energi listrik di Desa Sanglepongan pada periode Bulan JanuariDesember 2021 adalah sebesar 107.656 W, meningkat dari 2 tahun sebelumnya, dimana pada tahun 2020 jumlah kebutuhan energi listrik sebesar 107.262 W dan tahun 2019 sebesar 103.297 W. Persentase peningkatan penggunaan energi listrik dari tahun sebelumnya berdasarkan data aktual dengan data hasil prediksi adalah sebesar 4,13\% (akan meningkat $4.359 \mathrm{~W}$ dari tahun 2019 ke 2021) dan $0,37 \%$ (meningkat sebesar $394 \mathrm{~W}$ dari tahun 2020 ke 2021).

2. Pengggunaan metode moving average (MA) untuk memprediksi (forecasting) jumlah kebutuhan energi listrik di Desa Sanglepongan pada periode Januari-Desember 2021 dilkukukan dengan cara menggunakan data historis penggunaan energi listrik di desa sanglepongan 7 bula terakhir yang kemudian dianalisis dengan metode moving average (MA) untuk memprediksi jumlah kebutuhan energi listrik di Bulan Januari 2021 dan begitu seterusnya sampai bulan Desember 2021.

\section{DAFTAR PUSTAKA}

[1] Peraturan Pemerintah Republik Indonesia, vol. No 14. 2012.

[2] "Kantor Desa Sanglepongan, Sanglepongan," indowhere, 2020. https://indowhere.org/kantordesa-sanglepongan/local_government_officeplacec4cf868508c678b93ee9c4d10d42c44e.html

[3] F. H. Sumbung, Y. Letsoin, and D. Hardiantono, "Penentuan Kapasitas Dan Karakteristik Modul PV Pada Perencanaan Pembangunan PLTS Komunal Di Distrik Okaba," Mustek Anim Ha, vol. 5, no. 2, pp. 181-195, 2016.

[4] B. Render and J. Heizer, "Principles of operations management," 1996.

[5] A. S. Pabla et al., "All-optical bistable switching in a strained piezoelectric self-electro-optic effect device," Electronics Letters, vol. 30, no. 18, pp. 1521-1522, 1994. 